\title{
Remesas multi-direccionales y etnografia viajera
}

\author{
Lisa Maya Knauer*
}

\begin{abstract}
R esumen: Durante varios anos de hacer investigaciones con Cubanos en New York y Ia Habana, informantes en ambos lugares me han dado dinero, cartas y paquetes para llevar "al otro ladb". Como otros viajeros y turistas, soy mensajera, testigo y vicária para personas separadas por geografía, economía y política. También personas en ambas ciudades me han dado vidbos, fotos y grabaciones, o me han pedido a documentar algo para enseñar "allá". Fn este artículo, analizo algunas corrientes específicas de remesas y mandados: los que fluyen desde cuba hacia afuera, o sea, remesas reversas; El papel de remesas materiales y intangibles en la evolución de transnacionalismo religioso, particulamente en las religiones de origen africano; y el significadb de imágenes y sonidbs - o sea, remesas audiovisuales.

Palabras-clave: remesas, religiones afrocubanas, transnacionalismo, irmigrantes abanos, diáspora, medios de comunicación.
\end{abstract}

Al principio de Junio 2004, estaba con algunos amigos Cubanos en una rumba en el B ronx. L a palabra "rumba" refiera a un género o complejo de música, canto y baile nacido en los barrios marginales de Cuba urbana en el siglo 19, nutrido por antecedentes africanos y españoles, pero también a un evento, fiesta 0 lugar donde se toca, se canta y se baila la rumba. Uno de los rumberos, cómo los que tocan y gozan rumba se llaman, sonrió con aprobación cuando vio que yo estaba tomando fotos. René, quien salió de Cuba en el puente de M ariel en 1980 y no ha regresado a su país nativo en 24 años, me dijo, "¿Tú vas a enseñar esas fotos en la Habana, verdad?" Era menos una pregunta que una carga para mí.

Hace unos años en M atanzas, Cuba, B ertina García me dio un paquete a llevar a su hermano Felipe, quien estaba viviendo en $\mathrm{N}$ ew

\footnotetext{
* Professora assistente de Antropologia e de Estudos A fricanos e Afro-A mericanos na U niversity of $M$ assachusetts Dartmouth, U.S.A. PhD. New York University, Program in A merican Studies. E-mail: Iknauer@UM assD.Edu
}

Y ork. Ese contuvo varios tabacos, una saya en los colores de la orisha Oyá, y una copia de la "letra del año," una serie de predicciones y consejos preparado por los babalaw os - sacerdotes en la religión afrocubana llamada "Ia regla de ocha" o "Santería" - el 1 de enero cada año.

Durante los años que he viajado entre $\mathrm{N}$ ew York y Cuba para hacer investigación de campo sobre cultura afrocubana, gente en cada lugar me ha solicitado a llevar dinero, cartas y paquetes a sus familiares y amistades "al otro lado." Yo no era única en esto; casi cada visitante llega a Cuba con maletas Ilenísimas de cosas mandadas por otra gente. Ese incluye emigrantes cubanos volviendo a visitar sus familias pero también muchos non-cubanos, turistas igual que investigadores. N os han hecho convertido en agentes en intercambios transnacionales entre Cuba y su diaspora.

M iembros de comunidades diaspóricas y gente en la patria - incluso si no pueden visitarse - non obstante quedan en contacto (GlickSchiller et al., 1994). Cartas y llamadas telefónicas permitan los emigrantes a participar en 
asuntos familiares y de la comunidad (Rouse, 1991). Pero quizás de importancia igual son los intercambios materiales: El dinero y mercancía que los inmigrantes mandan para ayudar a sus familias. En muchos países con diásporas grandes, remesas de estas diásporas forman una parte substancial de la economía nacional. ${ }^{1}$ Transnacionalismo no es solo un fenómeno al nivel del estado-nación o una abstracción. Si es una "estructura de sentimiento" (Williams, 1978) o una "comunidad imaginada" (A nderson, 1991), pero también un proceso material y corpóreo, algo vivido. A penas como hombres y mujeres "hacen" género, inmigrantes y sus familias de origen "hacen" transnacionalismo. La gente lo hace por sus propias acciones y movimientos corpóreos (emigrar, Ilamar por teléfono, mandar paquetes), pero a veces encuentran limites físicos y legal es, y requieren otras personas para actualizar sus deseos y necesidades.

Al principio estas tareas parecían tangenciales al "verdadero" sujeto de mi investigación - música y religión afrocubana. Recibiendo y cargando cosas y mensajes eran solamente favores que hice para amigos. Sin embargo, yo gradual mente me di cuenta que esta circulación de mercancía e información era una parte crítico de la sustancia de lo que me interesaba. L levando paquetes y dinero, yo experimenté en carne propia el extensor y significado de los flujos transnacional es entre Cuba y su diáspora. E sos intercambios materiales eran parte del mismo proceso por lo cual las prácticas culturales racializadas constituyeron una comunidad translocal. Enfocando en "transnacionalismo desde abajo" (Guarnizo and Smith, 1999), me obligó a aprender las sutilezas de conducir trabajo de campo en locales múltiples, y negociar los campos sociales complicados que los conectan.

$M$ ientras continué a viajar a Cuba y recibir mensajes, mercancías y, ocasional mente, cosas con valor económico para llevar a los Estados Unidos, empecé a analizar la economía de remesas y mandados como una circulación multi-direccional. L a mayor parte de los estudios de remesas enfoquen en el dinero y mercancías

1. Stepick (1995) notes, for example, that remittances from Haitian emigres are the single largest source of revenue in Haiti's national economy. los transmigrantes mandan "a la patria" (Glick Schiller et al., 1994). L evitt (1997) sugiere que los transmigrantes dominicanos son portadores de "remesas sociales" en ambas direcciones. Cuando visitan a la República D ominicana, traen ideas, valores, modas de los EU, y vuelven a los EU con infusiones frescas de cultura y tradiciones de la patria.

Non obstante, mi obra extiende esas definiciones. Remesas sociales, definidos por L evitt, frecuentemente son las influencias cultural es que los transmigrantes absorban inconscientemente en cada local (L evitt, 1997). No obstante, los transmigrantes son los agentes más activos en su escenario. Yo analizo cómo sujetos localizados - Cubanos quienes tienen pocas oportunidades a salir de su país - deliberadamente mandan mensajes culturales y espirituales, también artículos de valor material, a ellos "al otro lado". Esas remesas cultural es frecuentemente son incorporadas en objetos que son entregados a viajeros - quienes posiblemente no son cubanos. Su materialidad no es incidental, y en algunos casos tienen un val or (o potencial) económico significante. ${ }^{2}$

Yo describo este aspecto de la circulación entre Cuba y su diáspora como "remesas reversas". Y o las veo como una esfuerza consciente por cubanos a resistir las desigualdades de las remesas tradicionales. Cubanos usan remesas reversas para ubicarse como remitentes y no solamente recipientes de cosas que tienen valor cultural, social o económico. En este artículo, examino varias tipas de remesas reversas, mirando como funcionan materialmente, emocionalmente y simbólicamente.

M i primera experiencia con "remesas reversas" involucró objetos con valor espiritual, y entonces exploro como remesas son entretejidas con las prácticas transnacionales de las religiones afrocubanas. En muchos casos cuando me pidieron a llevar algo de significado ritual a Ios EU, había un componente audio-visual. En otros casos, sencillamente me dieron fotos, 0

2. In my doctoral dissertation, I discuss how Cubans who are involved in the emergent economy (both legal selfemployment and unlicensed small businesses) utilize the same mechanisms (i.e. sending goods or even money out of the country with travelers) to obtain revenue or seek investment opportunities (K nauer 2004). 
grabaciones (audio o video), o me pidieron a hacerlas. M i análisis de remesas "intangibles" entonces incluye el concepto de "remesas audiovisuales".

M i investigación coincidió con, y reflejó, una serie de cambios rápidos y drásticos en la economía política y cultural de Cuba, y también en las relaciones entre Cuba y su diáspora. $M$ ientras Cuba ha tratado a recuperar de la devastación causada por el retiro de ayuda Soviética después de la disolución de la U nión Soviética en 1989, principalmente por enfocar en turismo extranjero y algunas empresas mixtas, el dólar americano ha tomado un papel mas y más significante, no solo al nivel nacional, pero a la misma vez en el cálculo intimo de la vida cotidiana, en la arena discursiva y en la imaginación popular. (Eckstein, 2003). El país efectivamente tiene un sistema de dos monedas corrientes, o quizás es más exacto a decir que la economía tiene varios dualismos. Hay un sector del dólar y un sector de pesos; también hay una economía informal grande y creciendo. No puedo detallar todas los matices en este escrito; pero algunos rasgos claves son que se pagan la mayoría de los salarios en pesos cubanos, pero las mercancías más deseables ( $y$, generalmente, de mejor calidad) solamente son disponibles en las tiendas que aceptan dólares (en la jerga cubana, "la shopping").

A la misma vez, ha sido un incremento constante en el tráfico entre los habitantes de la isla y sus familiares y amigos quienes han emigrado. Mi discusión enfoque en los EU, residencia de la gran mayoría de los emigrantes cubanos y un país que tiene una relación única y peculiar con su vecino isleño; la historia y consideraciones geopolíticas han formado el contexto de transnacionalismo "de base".

$M$ as que 100,000 emigrantes cubanos visitan a Cuba cada año. Otros índices del contacto cercano y continuo entre emigrantes cubanos y su patria es el incremento de remesas (el estimado es entre $\$ 600$ millones y $\$ 1$ billón anualmente, casi igual al ingreso total de turismo) $y$, desde el establecimiento de servicio telefónico directo entre los EU y Cuba en los 90, una explosión de comunicación tel efónica (Duany, 2001).
En esta manera, los emigrantes cubanos residentes en EU parecen inmigrantes de la mayoría de los otros países del mundo, quienes tratan a ayudar sus familias en la patria. Pero, como yo noto, este tráfico no es limitado a emigrantes cubanos. D ebido al bloqueo económico, y restricciones impuestas por $C$ uba y los EU en inmigración y viajes, ni ciudadanos cubanos ni emigrantes cubanos residentes en EU pueden viajar tan libremente como quisieran. A unque muchos de los escritos sobre transnacionalismo y globalización enfatizan la movilidad de personas, mercancías e ideas, es importante a recordar que estos no son procesos ni uniformes ni iguales. La movilidad es relativa y diferenciada por raza, género, recursos económicos y estatus legal. L as políticas y practicas varían entre países, tanto los que mandan como los que reciben. Todos los transmigrantes no son igualmente capaces de crear proyectos transnacionales en sus patrias.

En el caso de los EU, la política extranjera y domestica, y ideología toman un papel importante. M ientras la política de inmigración privilegia los inmigrantes cubanos en muchos aspectos, la comunidad "en exilio" ha forzado el gobierno a adoptar restricciones duras en cuanto a viajes y comunicación entre Cuba y Ios EU. El gobierno cubano, por su parte, restringe la movilidad de sus ciudadanos; obtener permiso a sal ir del país para estudiar, trabajar, 0 visitar a sus familiares en el extranjero no es fácil. Emigrantes cubanos no pueden hacer inversiones o comprar propiedad en Cuba; no pueden ocuparse con el mismo tipo de proyectos como emigrantes de otros países para aumentar su estatus. A unque algunas organizaciones cubanas en los EU mandan ayuda material (libros, equipos médicos), la mayoría de las inversiones de los emigrantes cubanos van directamente a sus familias. Al lado de divisa y cosas domesticas, cubanos tratan a mandar cosas que pueden servir para un pequeño negocio: las herramientas para arreglar relojes, pintura de uñas para manicuras; bolsas de cuentas para hacer los collares usados por santeros; medias, calzoncillos, cepillas de dientes, aretes baratos que se compran barato en las tiendas de descuenta en los EU y se vende de nuevo en la Habana. 
L os non-cubanos juegan un papel esencial por varias razones. A unque la ley de los EU dificulta los viajes de ciudadanos americanos a Cuba, somos relativamente más móviles que muchos emigrantes cubanos residentes en $\mathrm{EU}$, particularmente los quellegaron en el puente de Mariel y después. Las primeras ondas de emigrantes pos-revolucionarios provinieron de las clases elites y profesionales, quienes pudieron movilizar su propia capital social y las programas especiales gobiérnales de asistencia para regañar un nivel de prosperidad económica. Pero, las siguientes ondas de inmigrantes representaron un espectro socio-económico más amplio. A unque el retrato de los "M arielitos" como criminales y delincuentes por los dos gobiernos y la comunidad "cubana-americana" era muy exagerado, habían personas quienes tenían pasados criminales en Cuba, y otros adquirieron un record criminal en los EU (en al gunos casos después de darse cuenta que era difícil lograr el "sueño americano" por vías legales, particularmente si uno era restringido por idioma y prejuicios raciales o étnicos). U na proporción notable de los cubanos que emigraron a partir del 1980 era gente de color, y los bal seros de los 90 eran desproporcionadamente varones desempleados o subempleados; entonces ellos han sido afectados por las mismas desigual dades estructurales que otros hombres de color de la clase obrera. Ellos también encontraron un clima menos receptiva en losEU - un mercado laboral más apretado, hostilidad por parte de la comunidad "exiliada" ya establecida. M uchos quedan en trabajos de bajo ingreso o la economía informal. Es difícil ahorrar suficiente dinero para mandar remesas y viajar a Cuba, porque los gastos de los viajes son considerables. No hay vuelos baratos a Cuba y obtener pasaportes y avisados son procesos costosos y lentos. ${ }^{3}$

Hasta el final de los 70, Cuba no permitió los emigrantes a visitar, y aun después del cambio de la política cubana, obstáculos permanecen

3. In the spring of 2004, the U.S. Treasury Department amended its rules to further restrict Cuban immigrants' ability to visit and send money to their families. As of June 30, 2004, Cuban immigrants are only allowed to visit their families in Cuba once every three years, and can only send money to immediate family members. There have been widespread protests by Cuban immigrants, principally in Miami. en ambos lados. A demás, incluso los inmigrantes quienes puedan regresar legalmente son mal dispuestos a visitar hasta que han logrado unos marcos visibles de éxito. Un informante me dijo que necesitaba al menos $\$ 3,000$ sobre los gastos del viaje para comprar regalos y entretener su familia y amistades. Inmigrantes se preocupan de poder "representar" enfrente de sus familias y poder satisfacer las demandas económicas y emocionales de sus familias.

Porque un inmigrante cubano en los EU puede mandar solamente $\$ 300$ cada cuarto a un hogar en Cuba, las personas regularmente entrampan las regulaciones por llevar divisa 0 mandar divisa con otra gente. $M$ andar paquetes por un servicio especial izado es extremamente caro (en N ew Y ork, al rededor de \$15 por libra). Cuba trata de prevenir la importación de mercancía por individuos, y los oficiales de la aerolínea estatal y la aduana cubana vigilan mas a los emigrantes cubanos que extranjeros cuando entran al país (registran sus maletas, muchas veces confiscan artículos o demandan derechos exorbitantes para el sobrepeso o sobornos). Sucede que los cubanos tienden a contar con las maletas de los viajeros no cubanos para complementar sus obligaciones.

$M$ andar remesas - efectivo, cosas religiosas, material es audiovisual es - con un individuo invariablemente inserta esta persona en las redes sociales de uno - como mensajero, mediador $y$, muchas veces, vicario. Tanto el remitente como el recipiente tienen la expectativa que se pasarán las cosas literalmente de mano a mano, particularmente cuando hay dinero.

Paquetes de café y anillos de esponsales: remesas reversas

En enero de 1999, Caridad M oré apretó un paquete pequeño en mi mano cuando visité su casa en M arianao, un barrio de la H abana. Ese contuvo anillos de esponsales para su hijo Pedro, quien había mudado a $\mathrm{N}$ ew York un mes antes cuando su avisado de afiancé fue aprobado por Ios EU. Su felicidad que su hijo único iba a casarse era atenuada por su frustración con las políticas que no la permitiera a asistir la boda. L a pareja había decidido a renunciar los anillos de esponsales para ahorrar dinero para la boda, 
y eran emocionados por el gesto de Caridad porque entendieron tan caro era un juego de anillos para ella.

L a comida dispara una repuesta emocional muy fuerte en los inmigrantes. Cubanos en $\mathrm{N}$ ew York, como otros inmigrantes, pasan horas discutiendo la comida "de allá" - de los méritos del famoso helado de Coppelia, hasta las recetas preferidas para lechón asado. Cuando cubanos mandan comida a sus familiares emigrantes, están recordando ellos de lo que dejaron atrás. Gladys Casanova manda pequeños paquetes de café molido a su hermano J ulián en N ew Y ork. En una ocasión, Caridad M ore me pidió a grabar en video la preparación y consumo de al gunos platos preferidos de Pedro. M ientras yo la seguí, ella improvisó una narración constante, con detalles de la cocina y de la sazón. Ella continuó a comentar sobre el sabor durante nuestra comida y después cogió la cámara para que yo pudiera verificar sus pretensiones.

A I lado de evocar la nostal gia, estas remesas reversas permiten los cubanos a agradecer la ayuda que reciben de sus familiares emigrantes. Pero también permiten a estos sujetos localizados a defender su agencia. En ubicarse - si solo para un momento - como remitentes, pueden al iviar una parte de la incomodidad que ellos sienten como recipientes de caridad. Esta reversión sutilmente renegocia sus relaciones con los cubanos en el extranjero. Cuando Gladys manda una revista de música cubana editado en la Habana a Julián - algo que él no puede obtener en los EU - está diciéndole que ella, también, contribuye al go de valor a su relación. Pero la renegociación no es solamente de parte del cubano particular. EI monólogo de Caridad invita a Pedro a pensar no solo en ella pero en la H abana y Cuba. Ella esta tratando de evocar un sentido de pertenencia a un lugar.

\section{Remesas religiosas}

Encajados dentro los flujos mayores de remesas son ideas, información y objetos material es relacionados a las religiones afrocubanas. Cuando Pedro M oré manda dinero a Caridad para hacer ofrendas a las orishas, eso es una remesa religiosa. El dinero puede ser mandado - llevado para pagar una ceremonia o comprar objetos religiosos, o para satisfacer las necesidades espirituales de la familia de uno. Yo defino remesas religiosas por varios criterios: cosas que tienen un val or espiritual inherente 0 imputado; cosas o dinero mandado para complementar una obligación religiosa (por uno mismo o para la familia de uno), o que son mandados a familiares rituales sin tener una función espiritual explicita. A unque yo considero la función de fotos y videos de ceremonias entre mi análisis de remesas audiovisuales, también los clasifico como remesas religiosas, particularmente porque documentación ha ganado aceptación en muchas ceremonias con aspectos transnacionales.

M i participación inicial en la circulación de remesas religiosas consistió en llevar algo de Cuba para un emigrante cubano quien no había regresado a su país en 14 años. Era muy tarde de noche cuando la ex suegra de F élix llegó a la casa donde yo estaba quedando en la Habana en septiembre de 1994. Ella era una mujer de unos 60 años, prieta y flaca pero fuerte, y se comportó con una dignidad reservada. Ella cogió el sobre que Félix me dio hace unos días en $\mathrm{N}$ ew York, con cientos de dólares para sus hijas. A ntes de empezar el viaje largo a los al rededores de la ciudad, ella sacó un amuleto de plata de su monedero y me dio, diciendo, "Es la hacha de Changó. Felix entenderá porque le estoy mandando."

A ños después, cuando empecé a investigar las religiones afrocubanas en serio y participar mas concientemente en la transmisión de remesas y mandados, noté varios fenómenos casi simultáneamente. U no era de muchas de las remesas mandadas por inmigrantes cubanos eran destinado o por familiares santorales, o para las necesidades espirituales para familiares biológicos. A sí como la popularidad de las religiones afrocubanas creció en la isla - junto con los gastos - cubanos buscaron ayuda de sus familiares emigrantes para su vida religiosa. En cuanto a los inmigrantes cubanos en $\mathrm{New}$ Y ork se pusieron mas religiosamente, eran mas preocupados por, o conciente de, las necesidades o deseos religiosos de sus familias. A sí como los emigrantes buscan maneras de mantener una presencia en la patria y aumentando su prestigio, ayudando a sus familiares a iniciarse en la 
religión se convierte en un símbolo de estatus, 0 una forma de inversión.

L as cosas que las personas han mandado como remesas religiosas reversas, al gunos son objetos que son difíciles a obtener en los EU, 0 cosas que son disponibles allá pero se cree que el producto cubano es más potente 0 eficaz. Cuando Eugenia B rindis en la Habana manda un pedazo de cascarilla, una sustancia yesosa que se usa en numerosos rituales, a su hijo Pupy Insua en $\mathrm{New}$ York (quien no ha llamado en año), le está mandando energía espi ritual, pero a la misma vez recordándole de sus deberes para él mismo y para su familia.

A unque quizás Felipe Villamil hubiera podido obtener la información en la letra del año mandado por su hermana B ertina por otras vías, su acto afirmó las cuerdas religiosas que unen su familia extendida, y el liderazgo de Felipe entre ella. Del otro lado, creyentes en los EU (Cubanos y no cubanos) piden a los viajeros a traer cosas de Cuba con usos religiosos: tabacos, ciertas hierbas que solo crecen en Cuba, tambores miniaturas para un altar.

\section{Remesas audiovisuales y ritos transnacionales}

Los medios electrónicos y audiovisuales toman un papel importante en construir y mantener los lazos transnacional es entre cubanos y emigrantes. A unque los medios oficiales en IosEU y Cuba son muy distintos en su naturaleza y estructura (Cuba solo tiene 2 canales estatales y una dieta muy limitada de programación), ningún ofrece un retrato completo de la otra sociedad. Pero los huecos y tergiversaciones en los esferos oficiales son Ilenados o contradichos hasta cierta medida por medios que circulan por vías informales. El significando de esas remesas audiovisuales esta formado por la naturaleza especifica del "mediascape" (A ppadurai, 1993) y los factores geopolíticos que labran la comunicación entre cubanos y emigrantes.

Televisión toma un papel central en la mayoría de hogares cubanos. Cuba tuvo una industria de cine y televisión antes de 1959 y el gobierno revolucionario vio TV como un mecanismo importante de educación (y propaganda), y garantizo que los televisores eran muy econó- micos. Resulta que virtual mente cada hogar tiene al menos un televisor, y aunque solo son 2 canales, muchas personas mantienen el TV encendido constantemente. L os V CRs son más difícil a obtener; solamente se vende en las tiendas de dólar con precios altos. ${ }^{4}$

M ientras la tecnología de video y fotografía se han convertido más accesible, imágenes se han convertido en un elemento importante en los flujos bidireccionales de remesas de cual quier tipa. Hasta hace poco, emigrantes Cubanos frecuentemente mandaron o trajeron videos a sus familiares en Cuba. ${ }^{5}$ E sos incluyeron grabaciones piratas de programas populares de los canales castellanos de los EU ("EI Show de Cristina", que mezcla aspectos de "Oprah" y "J erry Springer", es muy popular), "cartas de video" y grabaciones de eventos familias como fiestas de cumpleaños y bodas. Esos permiten personas separadas por geografía, política y economía a entrar en el mismo "mundo de medios." (Ginsburg, A bu-L ughod and Larkin, 2002). Por mediación de videos de familia y fotos, los emigrantes cubanos pueden representarse, o ser representados, en la patria.

$M$ ateriales audiovisual es no son solamente una manera de mantener contacto, pero son integrales en como cubano y emigrantes producen y negocian sus identidades respectivas. Como Hall (1986) y Ginsburg (1995), entre otros, mantienen, en un mundo formado de medios masivos de comunicación, representación no es incidental a la formación de identidades; por el contrario, las identidades son hechas por representación. Los medios de comunicación baratos permiten a grupos que anteriormente tenían poco acceso a esas tecnologías a convertirse en productores activos de sus propios imágenes, en vez de ser sencillamente consu-

\footnotetext{
4. The government has attempted to establish a monopoly over audiovisual technology by prohibiting the private importation of VCRs or even replacement parts. There are also bans on the importation of other home appliances such as blenders.

5. Cuban customs and immigration officials have started to confiscate videocassettes from the suitcases of Cuban emigres. I have heard conflicting reports about the reasons for this - that the government is supposedly concerned that people may be importing anti-government propaganda. It certainly cannot be because they worry about the subversive influence of U.S. popular culture as Hollywood films are a regular feature of Cuba's television programming.
} 
midores y sujetos de imágenes producidos por otros. (A ufderheide, 1993; Turner, 1995).

Este nos permite a re-pensar la circulación de medios caseros (y comercial) entre Cubanos y emigrantes. R umberos emigrantes cubanos en New York se preocupan de que su producción cultural será visible en Cuba, para que gente en Cuba sepan que hay cubanos en N ew York quienes están luchando para mantener la vitalidad de una practica cul tural marginalizada. En la viñeta que abre este articulo, la demanda de René, que yo enseñaré fotos de él cantando rumba en el Bronx (N ew York) a gente en la Habana, articula esos deseos con fuera. Cubanos en la isla, por su parte, quieren asegurar que los emigrantes no olviden de ellos. Cubanos se producen como cubanos por la construcción activa de medios audiovisuales destinados por sus familiares y amistades emigrantes. Emigrantes, por su parte, se producen como cubanos y como personas diaspóricas por mandar mensajes mediados a su gente en Cuba.

$\mathrm{H}$ ay una aceptación creciente - tanto en la isla como en la diáspora - que la nación se convierte en una transnación. (E ckstein, 2003; Duany, 2000). Las personas involucradas en música y religión afrocubana tienden a verse como miembros del mismo medio ambiente, 0 comunidad, que tiene sitios múltiples. Una de las maneras que los miembros afirman su pertenencia y solidaridad es por el uso de medios audiovisuales.

\section{Remesas audiovisuales y} transnacionalismo religioso

L as tecnologías audiovisuales han tomado papeles nuevos y potencialmente significantes en el transnacionalismo religiosos, particularmente en religiones de origen africano como la regla de ocha y palo monte (Burke, 2000). Transnacioalismo religioso tiene varias raíces: Cubanos ya iniciados en esas religiones antes de emigración; emigrantes quienes vuelven a Cuba para iniciarse o pagan para las iniciaciones de los familiares que quedaron atrás; y la creciente popularidad de esas religiones entre no cubanos, quienes ven a Cuba como la "M ecca" (Testa, 2003; K nauer, 2003). Esas religiones - lo mismo como candomble - funcionan por parentesco ritual (G regory, 1999; B randon, 1993). Cuando esos lazos rituales 0 santorales se extienden a través de fronteras nacionales, su usan fotos, grabaciones y videos para comunicar mensajes que no pueden ser capturados en una breve llamada tel efónica o carta, o para documentar trabajos hechos para la persona ausente.

Su uso está entretejido con otros flujos materiales y intangibles. A bajo, yo detallo como video y fotos eran utilizados para mediar un intercambio entre un emigrante cubano resi dente en los EU y su padrino en "palo monte" en Cuba, y como ambos individuos pretenden establecer y afirmar conexiones, mandan mensajes y acertar agencia.

En el verano de 2001, Samuel me pidió a llevar dinero y unos regalos a su padrino, Luis. L uis había mudado hace poco y no tenía teléfono, y era difícil a comunicarse. L uis había empezado una nueva relación con una mujer con dos hijas, y también había sufrido una isquemia cerebral, pues Samuel quería un reportaje a primera mano de sus condiciones de salud y vivencia, y también fotos. Cuando Samuel se fue para los EU, había confiado su prenda - la cazuela de hierro donde se cree viven los espíritus de palo - a Luis, y quería que él me enseñara para poder fotografiarla. Finalmente, Samuel había tenido problemas personales y profesionales, y por dificultades en comunicación no había podido buscar consejo y ayuda espiritual de L uis, y quería que yo fuera intermediaria.

M e costó la mayor parte de una mañana a llegar a la nueva casa de Luis, arriba de una loma en los alrededores de la Habana. Luis felizmente aceptó los regalos y me presionó por noticias de su ahijado. Cuando expliqué que Samuel me había pedido a tomar fotos y video, empezó a darme instrucciones. "A llí, esto es el televisor que compré con dinero que él me mandó. Que filmes esto." Me enseño a una cabaña pequeña donde mantuvo su prenda y hizo la mayoría de sus "trabajos." Entonces arregló el dinero y los regal os al rededor de la prenda de Samuel y me dijo a fotografiarlo.

Después de oír de los problemas de Samuel, se puso pensativo, y dijo que iba a hacer al guna adivinación para buscar las raíces, y ver como los espíritus Congos pudieron resolverlo. Empecé 
a salir, pensando que yo seria un obstácul o, pero Luis insistió que mi presencia era importante porque había estado en contacto directo con Samuel. También, Luis quiso que yo grabar todo en video para que Samuel pudiera ver las cosas hechas por su cuenta. L uis tiró los caracoles varias veces, hizo al gunas marcas con cascarilla, y tiró los caracoles de nuevo, mientras hizo comentarios. Cuando terminó, me dijo que quiso hacer una misa espiritual para Samuel, para solicitar la asistencia de los espíritus de los muertos.

Fijemos la fecha alrededor de mi horario porque yo era vicaria para Samuel. También tuve que comprar al gunos el ementos requeridos como velas, hierbas y aguardiente. Luis me recordó a Ilevar la cámara de video. El día citado otra vez hice el viaje por guagua y a pie, y comencemos a trabajar. Dora, la esposa, leyó del libro de oraciones que se usa en misas, Luis rezó y cantó y yo grabé. Un espíritu Congo bajó y montó a Luis, y empezó a formar preguntas, demandas y pronunciar remedios. Cuando el espíritu salió y la misa terminó, L uis me pidió ver el video en la pantalla de la cámara. L o estudió con cuidado, y quiso ver algunas partes otra vez. Después del almuerzo, me pidió a grabar una carta de video, para interpretar lo que sucedió en la misa - como hubiera hecho en persona si Samuel estuviera presente.

He contado estos sucesos en detalle para ilustrar como lo audiovisual se convierte en una parte integral en la transmisión de remesas y la actuación de rituales transnacionales. $L a$ evolución de estos encuentros también sugiere la circularidad de intercambios: llevando los regales y el mensaje de Samuel "produjo" los eventos que sucedieron. También enfatiza la agencia de los "sujetos" y su participación critica con las tecnologías audiovisuales; Luis no era un "ojo inocente" y aunque prefería que yo cogiera la cámara, tuvo una idea muy clara de lo que quería grabar y porque. Finalmente, sugiere preguntas sobre mi complicidad y participación en estos encuentros. L a mensajera frecuentemente es mas que una intermediaria neutral. Ella (o él) puede ser apoderado como delegado para el emigrante ausente, y algunas veces, se convierte en un vicario para esa persona.
Santero/as cuyas relaciones principales de parentesco ritual están fuera de Cuba pero quienes viajan a Cuba para ceremonias y los cubanos que hacen el trabajo ritual para turistas religiosas usan fotos y videos para documentar la autenticidad y exactitud de esas ceremonias. Para los turistas rituales y los trabajadores rituales cubanos, quienes posiblemente no se verán pronto, las fotos y los videos sirven como un registro tangible de su encuentro.

Un día en agosto 2001, N atalia Hernández subió nuestra escalera en la Habana para invitarme a una iniciación en lo cual ella estaba envuelta. "Esto es algo para tu tesis," me dijo. Explicó que tres mujeres habían ido a Cuba para "recibir cuchillo", el grado mal alto de iniciación que una mujer puede recibir en la santería Cubana (hombres también pueden recibir cuchillo). No pude asistir la mayor parte de los 3 días de ceremonias porque eran restringido a gente quien había recibido cuchillo, pero $\mathrm{N}$ atalia quiso que yo fuera el último día, que culminó en una serie elaborada de comidas ritual es. A ñadió, "Tengo un trabajo para ti. Traiga tu cámara. Quieren grabar el último día."

Dos días después llegué a la casa al quilada para la ceremonia y era aposentada en uno de los cuartos atrás, donde las tres iniciadas nuevas eran reunidas, vestidas de blanco brillante, cansadas pero felices. En el suelo al lado de cada mujer hubo un montón de cajas y bolsas. $N$ atal ia me explicó que era habitual para los que reciben cuchilla a regalar algo a todas las personas que trabajaron en la ceremonia, y añadió "Y ahora tienes que empezar a trabajar, porque debes grabar eso para que todos sepan que ellas hicieron todo correctamente." D os eran cubanas viviendo en los EU, me dijo, y la tercera era italiana.

M ientras arreglé mi lente, los babalawos y santeras mayores se pusieron en fila a la puerta $y$, uno por uno, pasaron enfrente de las tres mujeres para intercambiar saludos rituales y bendiciones, y recibir sus regales. Después de los mayores, las santeras más jóvenes quienes habían cocinado y limpiado hicieron cola para recibir sus regales más modestos. "Y tú también," Natalia me empujo adelante. "Hay algo para ti, porque la grabación que estás haciendo es parte del trabajo." Entonces, nos 
Ilamaron a una mesa larga, arreglado con platos blancos brillantes y vasos de cristal para empezar la primera de tres comidas. Natalia me dijo que debo grabar un poquito de todo "para que puedan ver que no dejemos ningún detalle."

M ientras yo filmé las santeras menores sirviendo la comida, los otros mantuvieron una narración corriente, mencionando los distintos platos como emergieron - particularmente las delicadezas como chivo y camarones y comentado sobre los sabores. Durante la última comida, el hombre que estaba presidiendo me llamó y empezó a hablar a los padrinos de las dos cubanas quienes habían venido de los EU - la audiencia final para la grabación. Él se identificó por su nombre ritual y su linaje, y afirmó que estas dos mujeres verdaderamente habían recibido cuchillo, que todo había salido muy bien, y que habían recibido muchas indicaciones positivas y bendiciones de los orishas. ${ }^{6} Y$ él añadió que mandó sus saludos calurosos a "nuestros hermanos y hermanas allá, los cubanos en Estados U nidos."

El día siguiente, hice copias de la grabación para las mujeres. La documentación en video era vestida como una parte importante de la ritualidad porque los padrinos de las mujeres y sus otros familiares rituales no pudieron estar presente para afirmar que todo estaba hecho correctamente; funciona casi como un certificado o una di ploma.

L a acrecencia de iniciaciones transnacionales ha conducido a la mayor aceptación de documentación con fotos, video y audio dentro de la ritualidad, y el reconocimiento de su utilidad particular. En la mayoría de las ceremonias con extranjeros que yo asistí había al guien presente - usualmente un familiar del nuevo iniciado con una cámara. Cuando cubanos residentes en otros países vuelven a Cuba para iniciaciones, los videos o fotos de esos eventos son un registro importante de las visitas demasiado cortas a su patria; tienen un significado intensamente personal y emocional para los visitantes y los

6. Cada vez que una persona recibe cualquier tipo de iniciación, tiene que peticionar a los orishas y pedirles (por adivinación) a hablar a los nuevos iniciados. Se supone que su consejo, llamado un ita, debe guiar la persona en esa nueva etapa de su vida. visitados. También permiten la participación vicaria de amigos y familiares en el exterior quienes no viajaban a Cuba para el ritual. Cuando X iomara Rodríguez, quien vive en $\mathrm{N} \mathrm{ew}$ York, llevó su hijo M ichel a Cuba para hacerle santo, me pidió a grabar la fiesta de tambores (Ilamado "toque de santo"). Ella enseñó el video a su hermano Chicho, también residente en $\mathrm{N}$ ew York, y M ichel lo ha enseñado a sus amistades en las comunidades de religiosos y tamboleros.

Cuando posible, Cubanos utilizan visitante para grabar eventos culturales y religiosos significantes para compartir con familiares ausentes. En el verano de 2002, Gloria A naya me invitó a una misa espiritual que ella organiza todos los años en el 31 de agosto para honorar a su mamá, quien era una espiritista renombrada. En particular, ella me invitó como representante de su hijo Román quien había emigrado a $\mathrm{N}$ ew York en 1999, y también para grabarlo y llevar el video a Román. "Quiero que él sepa que mantenemos la tradición," me contó, "y que vea que hacemos todo igual, y que todo está correcto." Cuando llegué, me presentó a todos como amiga de Román y aseguró que tuve un buen lugar para filmar sin obstrucción.

Cubanos también utilizan fotos y videos para sus propios fines, no solo para mandar a familia en los EU. Cuando Enrique Insua, quien vive en M iami, hizo santo a su nieto J ohnny en la Habana, la familia quiso garantizar que la fiesta del tambor era grabada. Johnny, un joven de 16 años, había recibido una diagnosis de cáncer del cerebro, y la prognosis médica era fea. L a familia también quiso que yo enseñara el video a Pupy, el tío-abuelo deJ ohnny, en $\mathrm{N}$ ew York pero el objetivo principal era tener un registro para ellos mismos. J ohnny murió un poco más que un año después de la ceremonia, y las fotos y videos son tesoros dentro del circulo familiar.

Los videos y fotos pueden servir como símbolos de estatus para los cubanos - santeros y santeras, babalawos y otros - que hacen el trabajo ritual; son una manera de demostrar que uno tiene ahijados extranjeros. En varias ocasiones, santeras o babalawos cubanos han sacado álbumes para enseñarme fotos de sus ahijados en Europa, A mérica L atina o los EU. 
Remesas audiovisuales y el "folclor"

Inmigrantes cubanos quienes son músicos o bailarines folclóricos son ansiosos a demostrar a sus familias, amigos y colegas en Cuba que todavía están "en talla", que ellos mantienen y desarrollan la tradición. I mágenes y grabaciones se convierten en una moneda corriente cultural que adquiere 0 gana valor principalmente por circulación. Inmigrantes pueden sentir la necesidad de justificar sus decisiones a venir a los EU, o mostrar que todavía "pertenecen" a la comunidad interpretativa de artistas folclóricas y rituales. A la inversa, cuando empecé a viajar a Cuba, personas quienes yo conocí allí me demandaban a llevar, en el próximo viaje, imágenes de rumbas en $\mathrm{N}$ ew York, o fotos de amigos y familiares a quienes no habían visto en años. Estos videos y fotos de eventos de rumbas y rituales en $\mathrm{New}$ York son circulados entre familia y otras redes sociales; se desplieguen fotos de familiares emigrantes en lugares prominentes en las salas de familias Cubanas, 0 en álbumes que se sacan y se muestran a visitas. Tener familiares afuera se ha convertido de un riesgo hasta un activo.

A veces, hay dos agendas en juego. Hace unos años atrás, cuando estaba planificando un viaje a Cuba, Stanley Insua me pidió a grabar cual quier cosa, con su papá Pupy, quien havivido en New York desde 1995, "porque nunca comunica con nosotros y quiero ver que ese sinvergüenza está haciendo. También mi abuela quiere ver esa cara fea."7 Pupy me invitó a un ensayo para la película Calle 54 . Varios otros artistas cubanos estaban presentes, incluyendo Orlando "Puntilla" Ríos (quien emigró en 1980) y Román Díaz A naya (ya mencionado). Cuando habían terminado el ensayo, Puntilla aprovechó de mi presencia y el hecho que pronto viajaría a Cuba para "representarse" (y los otros) a sus colegas en Cuba. Pensó que yo posiblemente vería al gunos de los músicos renombrados con quienes él, Román y Pupy habían trabajado, y

7. Cubanos usan términos de encariñamiento que serían insultos dentro de la cultura estadounidense de la clase media. Un hombre flaco será "el flaquito". M uchas veces esos términos son basados en el color de piel. Dentro de su círculo íntimo, se llama Stanley "el negrón". Se usan insultos irónicamente; se refiere a una persona quien ha estado fuera de contacto como "la descarada". se dirigió hacia ellos. Él presentó todos los músicos presente, notando los que no eran cubanos. "M ira," indicando a Felix Sanabria, "A quí tenemos un boricua quien ha estado con nosotros desde el principio." Esto fue un signo, según él, que la cultura afrocubana estaba floreciendo y pasando a otras comunidades. Después Ilamó a todos los otros para "decir al go a tu gente." La mayoría pronunciaron unas pocas palabras, casi formulaícas en su mezcla de saludo y afirmación. "Diles a todo el mundo que estoy bien, que estamos aquí reunido, que estamos manteniendo la cultura."

Cuando llegué en la Habana, el video era mostrado, discutido y disecado. Las personas comentaron sobre como se vieron sus familiares y colegas, y evaluaron críticamente la actuación: la selección de cantos, los pasos de los bailarines, quien tocaba y cómo. Se escrudiñaron los "mensajes" y se comentaron. Videos como este (y he llevado muchos) se ven repetidamente, y se circulan a otros quienes son ansiosos para una vista de sus seres queridos, o sencillamente curiosos de saber al go de los emigrantes cubanos en New York.

A veces, la documentalista visitante tiene que negociar las agendas divergentes del cubano en $\mathrm{N}$ ew York quien ha solicitado a grabar un evento en Cuba, y la gente en Cuba con sus propios mensajes. En mi primer viaje de investigación a Cuba en 1998, J osé A Iberto Casanova, quien salió de Cuba en una balsa en 1994 me dio una tarea. M e pidió a asistir al cumpleaños de su mamá M érida, que se celebraba con un día entero de fiesta y rumba en el patio compartido por varias familias. Cuando llegué, la fiesta ya estaba en proceso, y M eri y su hija M aritza se encargó de lo que yo iba a grabar. Primer una y después la otra me guió por el patio, diciéndome donde debería enfocar la cámara y dirigiendo los cel ebrantes. Eran muy conscientes de las imágenes que querían mandar a José A lberto en N ew Y ork. Intentaron el video como un aide-memoire y también para picar su conciencia. Meri quería que su hijo viera las caras de familiares a quienes él no había visto en 4 años, pero también a dejarle saber que la vida continuaba sin él. La mayoría de los mensajes eran jocosos, y muchas personas empezaron diciendo "Probablemente me has olvidado, 
pero yo soy tu tía [prima, vecino]" y continuaba diciéndole que todo estaba bien y que le extrañaba. M uchos mensajes contenían una nota de admonición: cuídate allá en el norte, y debes llamar a tu madre.

$M$ andando remesas y paquetes en esta manera es, entonces, un proceso intimo, personal y corpóreo. Tiene que ver tanto con la formación 0 el mantenimiento de lazos sociales entre individuos como con asistencia material. Y los mensajeros son agentes sociales también. Remitentes y recipientes tienen la expectativa que la "mula" no solamente llevará el paquete o el dinero personal mente, pero que también va a sentarse y tomar un café o comer una cena, y suplir la información en la carta o el video con un acontecimiento por primera mano. Para sujetos local izados, los que son privilegiados a viajar son una fuente rica de información sobre la vida "del otro lado, de allá". Esos encuentros se convierten, muchas veces, en una forma de "etnografía reversa." Gente en Cuba me preguntaba cosas intimas y detalladas sobre la "imponderabilia" de la vida cotidiana. A I gunos son interesados en como yo mismo vivo, al gunos quieren saber como viven "los cubanos" en los EU, y otros preguntan sobre uno u otro individuo. Pero sus preguntas frecuentemente son tan precisas como cualquier encuesta etnográfica. ¿Cuánto pago para un litro de leche, el alquiler de mi apartamento, un par de zapatos? Emigrantes cubanos en N ew Y ork, por su parte, quieren cuentas igualmente detall adas de la vida cotidiana en Cuba. A unque este reverso de rol no elimina las relaciones estructurales de desigualdad, impone otros dinámicos.

Llevar remesas y mandados se convirtió en una técnica efectiva para trazar los contornos de los campos sociales transnacionales y entender su materialidad. Originalmente, personas en $\mathrm{New}$ York me dieron cosas para llevar a Cuba y eso me dio referencias en Cuba. Pero desde el primer viaje, personas en Cuba me entregaron cosas para llevar a N ew Y ork, y así conocí personas por mediación de sus familiares en Cuba. También entendí que no estaba fuera del proceso que estudiaba, pero que participaba en crearlo a la misma vez.

Muchas veces cuando doy un video a al guien, el recipiente quiere verlo conmigo. Esto me permite a ver la Habana por los ojos de un cubano viviendo en N ew York, 0 al inverso, a ver como cubanos miran a sus compatriotas viviendo en los EU. Soy ubicada como participante en "encifrando" y "descifrando" estos mensajes mediados. (H all 1980).

Estos sujetos transnacionales son conectados íntimamente pero residen en distintos mundos y tienen sentidos divergentes de sus obligaciones y situaciones respectivas. Comparten el mismo "habitus" pero sus "mundos vividos" son distintos y disimilares. Muchas veces mediar implica decidiendo cual información debe ser transmitido, y como navegar el terreno incierto de los lazos emigrante-patria. Emigrantes cubanos con frecuencia sienten que sus familiares tienen expectativas no realistas. Empiezan a resentir sus demandas, y quejan que la gente en Cuba no entiende que "aquí la vida no es fácil", porque aunque se gana mas en $\mathrm{N}$ ew York, los gastos son mucho más al tos.

Por el otro lado, cubanos sienten que sus familiares en los EU no tienen una idea clara de sus dificultades. A veces, una persona me pide a transmitir una demanda que yo sé que su familiar no puede o no va a resolver. Sayle Insua me dio una carta para su papá, pidiéndole dinero para el primer aniversario de su iniciación como santera. Tuve que decidir como iba a presentar la demanda a Pupy, y que iba a decir a Sayle cuando me preguntó para la respuesta de su papá. Si digo que Pupy está pasando mucho trabajo en N ew Y ork, este disminuye su estatus en los ojos de su familia en Cuba, y promueve dudas sobre decisión de emigrar. Si digo que él está muy bien, esto levanta expectativas y potencialmente resentimiento - ¿Entonces, porque no manda mas dinero y porque no ha visitado?

Posiblemente este breve esquicio ha evocado mas preguntas que ha respondido. L as "áreas grises" y contradicciones sugieren desafíos éticos y metodológicos, tanto para conducir trabajo de campo como para escribir etnográfica. Son exacerbados por las relaciones de raza, genero, clase y nacionalidad que contextualizan mis relaciones con mis informantes y con la cultura afrocubana. Todavía se ven practicas culturales como la rumba y la santería por la lente de ambivalencia racial: son 
construido simultáneamente como raciales ("cosas de negros") y entonces marginales, y curiosidades folcloricizadas. L os que están luchando para legitimizar estas practicas, levanta su estatus y asegura recursos me ven como defensor - y quizás más poderosa precisamente porque soy "blanca", "americana" y una "estudiosa" y entonces tengo mas acceso a arenas como la A ssociação B rasileira de A ntropoloiga y las páginas de esta revista. La "etnográfica reversa" ya citado extiende a mis investigaciones y escritos. Las representaciones que yo y otros estudioso producimos de cubanos y emigrantes (y no solo las remesas audiovisuales que he grabado y llevado) también son parte del discurso en esta comunidad transnacional.

A bstract: During several years of conducting research with Cubans in New York and Havana, informants in both places have given me money, letters and padkages to take to the other side. Like other travelers and tourists, I am a messenger, witness and surrogate for people separated by geography, economics and politics. Also, people in both cities have given me videos, photos and recordings, or have asked me to document something to show "over there". In this article, I analyze some specific arrents of remittances and items that are sent: those than flow from aba to other places, that is, reverse remittances; the role of material and intangible remittances in the evolution of religious transnationalism, particularly in the religions of African origin; and the significance of images and sounds that is, audiovisual remittances.

K ey-words: remittances, afrocuban religion, transnationalism, diaspora, aban imigrants, audiovisual media.

\section{Referências}

A NDERSON, B enedict. Imagined communities. London and N ew York: Verso, 1991.

AUFDERHEIDE, Pat. The Video in the Villages Project: Videomaking with and by B razilian indians. VAR, v. 11, n. 2. 1993, p. 83-93.

BURKE, Nancy. Prepaid phone cards and photos of the saints: strategies and tools of transnational santeria in a Southwest city. Paper presented at the 3rd CRI Conference on Cuban and Cuban-A merican Studies, M iami, O ctober 18-21, 2000.

DUANY, J orge. Redes, remesas y paladares: La diáspora cubana desde una perspectiva transnacional. Nueva Sociedad (Venezuela), n. 174, 2001, p. 40-51.
ECK STEIN , Susan; B A RB ERIA , L orena. G rounding immigrant generations in history: Cuban-A mericans and their transnational ties. International Migration Review, v. 36, n. 3, Fall 2002, p. 799-837.

ECK STEIN , Susan. Diasporas and dollars: Transnational ties and the transformation of Cuba. Working Paper, n. 16, A ssociation for the Study of the Cuban Economy, 2003.

GINSBURG, Faye. M ediating culture: indigenous media, ethnographic film and the production of identity. In: DEVEREA UX, Leslie; HILLM AN, Roger (Eds.). F ield of vision: Essays in film studies, visual anthropology, and photography. Berkeley: U niversity of California Press, 1995, p. 256-291.

GINSB URG, Faye; ABU-LUGHOD, Lila; LARK IN, $B$ rian (Eds.). M edia worlds: A nthropology on new terrain. B erkeley: University of California Press, 2003.

GLICK-SCHIL LER, Nina; BASCH, Linda; BLANCSZANTON, Cristina (Eds.). Nations unbound: Transational projects, postcolonial predicaments, and deterritorialized $\mathrm{N}$ ation-States. L anghorne, PA: Gordon and B reach, 1994.

GREGORY, Steven. Santeria in N ew York. N ew Y ork: Garland Publishers, 2000.

HALL, Stuart. Cultural identity and cinematic representation. F ramework 86, 1986, p. 68-81.

Encoding/decoding. In: HA LL, Stuart et al. (Eds.). Culture, media, language. London: Hutchinson, 1990, p. 128-138.

KNAUER, Lisa M aya. Santeria entre los cubanos "de acá" y "deallá"Santeria entre los cubanos deaca y dealla: Religious transnationalism and the micropolitics of obligation. Paper presented at the $5^{\text {th }} \mathrm{CRI}$ Conference on Cuban and Cuban-A merican Studies, October 31, 2003.

Translocal Afrocuban culture: rumba and santeria in N ew York and Cuba. Unpublished doctoral dissertation, N ew York U niversity, 2004.

LEVITT, Peggy. Transnational Villagers.

TESTA, Silvina. La H abana como "la mecca" de le regla de ocha. Paper presented at the $5^{\text {th }} \mathrm{CRI}$ Conference on Cuban and Cuban-A merican Studies, Florida International U niversity, October 31, 2003.

TURNER, Terence. Representation, collaboration and mediation in contemporary ethnographic and indigenous media. VAR, v. 11. n. 2, Fall 1995, p. 102106.

WIL LIAM S, Raymond. Marxism and literature. Oxford: Oxford University Press, 1977.

Recebido em maIO de 2004 A provado em agosto de 2004 